\title{
О.Г. Леонова
}

\section{ИНАИЙСКО-РОССИЙСКИЕ ОТНОШЕНИЯ В XXI ВЕКЕ: ВЗГАЯА С АРУГОЙ СТОРОНЫ*}

Аннотация. В статье анализируется точка зрения индийских экспертов о состоянии дел в сфере индийско-российских отношений, о существующих проблемах и путях их разрешения. Делается вывод о том, что будущее индийско-российских отнотений связано с исторически сложившимся партнерством двух стран, с отсутствием конфликта национальных интересов, со схожестью позиций по актуальным вопросам современности.

Ключевые слова: Индия, Россия, взаимоотночения, стратегическое партнерство, трудности, проблемы, перспективы развития.

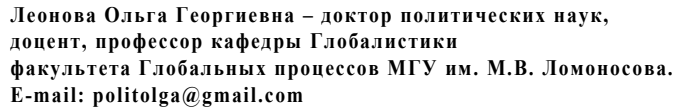

Леонова Ольга Георгиевна - доктор политических наук, доцент, профессор кафедры Глобалистики

факультета Глобальных процессов МГУ им. М.В. Ломоносова.

E-mail: politolga@gmail.com

\section{O.G. Leonova. Indian-Russian Relations in the $21^{\text {st }}$ Century: A View from} the Other Side

Abstract. The article analyzes the Indian experts view on Indian-Russian relations, existing problems and ways of their solution. The author concludes that the future of Indian-Russia relations is connected with the historical partnership between the two countries, with no conflict of national interest and similarity of positions on topical issues.

Keywords: India, Russia, relationship, strategic partnership, difficulties, problems, prospects of development.

Leonova Olga Georgievna - Doctor of Political Sciences,

Associate Professor, Professor of the Department

of Global studies of the Faculty of Global Processes

of Lomonosov Moscow State University.

E-mail: politolga@gmail.com

* Исследование выполнено при поддержке РФФИ гранта № 15-06-03655. 
В октябре 2016 г. представитель Московского государственного университета им. М.В. Ломоносова впервые участвовал в торжественных мероприятиях крупнейшего в Индии Пенджабского университета в г. Чандигарх, посвященных празднованию дня рождения Махатмы Ганди, а также в круглом столе по развитию сотрудничества России и Индии как партнеров по БРИКС. Стоит отметить, что Индия в течение года являлась председателем неформального объединения БРИКС, этим объясняется повышенный интерес в стране к данной теме.

В феврале этого года делегация МГУ была приглашена в Университет города Мандсаур, для участия в Международной конференции «Empowerment through Education, Ethics and Entrepreneurship: the Agenda for BRICS» («Расширение возможностей через образование, этику и предпринимательство - новая повестка для БРИКС») ${ }^{1}$.

В обоих случаях индийская сторона выразила большую заинтересованность в сотрудничестве и кооперации между нашими университетами.

Bce это подтверждает известную нам аксиому: в Индии люди питают очень теплые и дружественные чувства к России и заинтересованы развивать и углублять наши традиционно тесные взаимоотношения.

Индия является партнером России по БРИКС, а с недавнего времени и по Шанхайской организации сотрудничества, процесс вступления в которую был инициирован на совместном саммите БРИКС и ШОС в Уфе в 2015 г.

Удивительно, но об индийско-российских отношениях в самой Индии написано не так уж и много. Гораздо более обширная литература посвящена анализу взаимоотношений Индии с такими странами, как Китай, Пакистан, Иран, Турция, Индонезия и с др. Большинство доступных нам источников на тему российско-индийских отношений - это труды российских ученых, которые представляют взгляд из России. В итоге оценка характера и содержания этих отношений предстает односторонней, а нередко и завышенной.

Между тем для дальнейшего их эффективного развития необходимо объективно оценить результаты, выявить имеющиеся трудности и поставить диагноз. Выявление узловых точек, которые тормозят поступательный процесс, позволит «выписать лекарство» и определить меры, которые помогут укрепить наше стратегическое партнерство.

В этом смысле интересно проанализировать оценки, которые дают взаимоотношениям России и Индии индийские ученые, эксперты и политики. Большинство из них считают, что сегодня эти взаимоотношения находятся на переломном этапе.

1. Здесь и далее перевод автора. 
С распадом Советского Союза целая эпоха современной истории пришла к своему концу, а индийско-советские отношения, которые зародились и успешно развивались в советскую эпоху, сегодня находятся в ситуации, которая имеет множество потенциальных сценариев развития: как позитивных, так и негативных.

\section{История проблемы}

Начало холодной войны, которое совпало с обретением Индией своей независимости в 1947 г., стимулировало интерес Советского Союза к этой стране. В результате конфликта с Китаем и неудачного опыта взаимоотношений с США, который показал Америку как ненадежного партнера, Индия осознала необходимость выстраивания тесных и дружественных отношений именно с Москвой, что и завершилось в 1971 г. подписанием договора о дружбе.

Поставки советского оружия оказались жизненно важным фактором для Индии и во многом определили успех ее военных действий в Восточной Бенгалии в 1971 г. Впоследствии именно эти военные закупки стали основой нашего экономического партнерства на многие десятилетия вперед. И сегодня Индия остается вторым крупнейшим экспортером российского оружия после Китая. С течением времени отношения Дели с Москвой постепенно становились все более тесными, однако и в процессе их развития Индия постоянно подчеркивала свое право на независимость и суверенитет и принципиально оставалась вне политических блоков времен холодной войны.

Индийско-советские отношения прошли через тяжелую фазу и даже пережили некоторый период хаоса в конце правления М.С. Горбачёва и в начале распада Советского Союза. Россия как наследница СССР приняла на себя ответственность по выполнению всех обязательств по договорам, контрактам и соглашениям, заключенным ранее с Индией.

В начале 1990-х годов российская экономика и внешняя политика переживали болезненные трансформации. Сегодня в Индии с горечью вспоминают, что в сфере внешней политики России доминирующим был провозглашен европейский вектор и разворот на Запад, преимущественно в сторону США. Интеграция с Европой стала приоритетной целью, много говорилось об «общем европейском доме от Урала до Атлантики». Во времена президента Б.Н. Ельцина Россия позиционировала себя как европейская держава, позабыв о том, что большая часть ее территории все же находится в Азии. Ее отношения со странами Азии, включая Индию, все более отходили на задний план.

Во взаимоотношениях с Россией Индия в итоге потеряла все свои традиционные преимущества в торговле и в других сферах экономического сотрудничества, и ей пришлось перейти на крайне невыгодные для нее расчеты 
в иностранной валюте. Неудивительно, что объемы такой торговли стали быстро сокращаться, и осуществлялась она преимущественно в форме экспорта товаров из Индии в качестве оплаты ее долгов прошлых лет. До конца 1990-х годов взаимная торговля оставалась стагнирующей на уровне 1-2 млн долл. Из-за хаоса в экономике России и неразберихи в условиях поставок цены на оружие, которое закупала Индия в нашей стране, выросли в разы до нереального уровня.

Положение дел, казалось, начало меняться после визита Президента Б.Н. Ельцина в Индию в январе 1993 г. Предполагалось, что этот визит положит начало новому этапу взаимовыгодных взаимоотношений наших стран. Действительно, первый шаг был сделан: проблема ревальвации (переоценки) огромного долга, накопленного Индией в советский период, постепенно начала решаться. Разумеется, речь не шла об отмене или сокращении долга, однако условия его выплаты были значительно облегчены для Индии (35\% этого долга было реструктурировано и для его выплаты были определены более легкие условия, и в целом бремя долга Индии значительно сократилось).

Однако вскоре стало очевидно: в новых условиях торговые связи России и Индии приходят к своему логическому концу. Казалось уже, ничто не поможет нам вернуться к традиционной кооперации и привычному тесному сотрудничеству двух стран. Сами базовые параметры наших взаимоотношений изменились безвозвратно: Россия больше не собиралась оплачивать импорт товаров из Индии в рупиях, даже вопрос об инвестициях России в подъем индийской экономики не стоял, не говоря уже о том, чтобы получать возврат кредитов экспортом индийских товаров. В силу вступила прагматическая политика, которая диктовала жесткие условия торговли в иностранной валюте. Хотя Россия на словах соглашалась повысить свои взаимоотношения с Индией до уровня стратегического партнерства, но стало ясно, что возврата к особым отношениям между странами быть не может.

Новые перспективы развития наших взаимоотношений наметились, когда Президентом Российской Федерации стал В.В. Путин.

Россия под руководством нового президента быстро восстанавливала свои утраченные в 1990-е годы позиции, ее экономический рост достигал 5-6\% в год, страна представляла собой один из самых быстрорастущих рынков в мире. Однако в последние несколько лет из-за падения цен на нефть и введения западных санкций экономика нашей страны переживает определенные трудности, которые, впрочем, не смущают индийскую сторону. В Индии верят в Россию и считают, что страна, обладающая такими природными ресурсами и таким качественным человеческим капиталом, развитыми высокими технологиями и фундаментальной наукой, остается сильным политическим и экономическим полюсом глобального мира, влиятельной военной державой. 
Взаимоотношения с Россией жизненно важны для Индии. Они прошли проверку временем и всегда основывались на взаимном доверии и поддержке простого народа обеих стран. Но, к сожалению, индийские эксперты констатировали и тот факт, что сегодня Индия не прикладывает особых усилий, чтобы возродить эти отношения до уровня взаимовыгодного и эффективного сотрудничества, как это было в прошлом [10, с. 268].

Это вызывает определенное удивление, если учесть, что россияне испытывают особую любовь к Индии, эта страна пользуется в России гораздо бо́льшим уважением и имеет бо́льший авторитет, чем в странах Запада. Сначала Советский Союз, а затем Россия как его наследница поддерживали Индию в некоторых критически серьезных политических ситуациях. Россия поддержала Индию в ее позиции по штату Кашмир, в ее территориальных и других спорах с Пакистаном и даже предлагала свою помощь в урегулировании этой проблемы. Советский Союз был на стороне Индии во время бангладешского кризиса в 1971 г. В начале 1990 -х годов, несмотря на давление со стороны США и администрации Б. Клинтона, Россия поставляла Индии криогенные двигатели, предназначенные для ее программы космических исследований, она отказалась участвовать в санкциях против этой страны, которые были на нее наложены Западом после испытания ядерного оружия в 1998 г. Более того, в этом же году Россия подписала с Индией соглашение о военном и технологическом сотрудничестве, рассчитанное на десять лет, и подтвердила свое решение о поставке двух ядерных реакторов для атомной электростанции в Куданкуламе, продолжала бесперебойные поставки вооружения и запасных частей для ее вооруженных сил. Примечательно, что в это время Россия оставалась единственной крупной страной мира, которая воздержалась от поставок вооружения Пакистану. Это был прекрасный пример того, как наша страна учитывала в своей внешней политике интересы безопасности своего давнего партнера.

Однако намерения Индии начать крупномасштабные военные поставки из США (несмотря на чувствительную нагрузку для своего бюджета) заставили Россию искать другие рынки сбыта своего оружия. Среди них именно Пакистан предложил нашей стране наилучшие условия, в результат чего в середине 2014 г. было решено продать ему несколько знаменитых вертолетов МИ-35.

Несмотря на это, военное сотрудничество России и Индии продолжалось. Именно Индия была единственной страной, с которой Советский Союз, а затем Россия делились своими передовыми технологиями, в том числе в военной сфере ${ }^{2}$. Среди наиболее важных примеров: аренда атомной

2. В единичных случаях второй такой страной был Китай. 
подводной лодки, совместное сотрудничество и лицензионное производство в Индии самолетов СУ-30 и танков Т-90, поставка оборудования для атомных реакторов, технологии полного производства одного из самых современных вертолетов с разрешением продавать готовую продукцию его в третьи страны, заказ на строительство российского фрегата «Триканд», передача в Индию нового самолета «Викрамадитья» и т.д.

В самой Индии признают, что Россия сегодня является самым важным и надежным партнером в сфере обеспечения ее безопасности.

\section{Эволюция статуса взаимоотношений Авух стран}

Во время визита В.В. Путина в Индию в 2000 г. наши страны реанимировали свои взаимоотношения до уровня стратегического партнерства, что и было отмечено в специальной Декларации.

В декабре 2010 г. во время визита в Индию Президента РФ Д.А. Медведева наши взаимоотношения были повышены до статуса специального и привилегированного партнерства. Тем самым была создана институциональная основа для дальнейшего развития двусторонних взаимоотношений наших стран. С тех пор главы государств или правительств ежегодно встречаются на специальных саммитах двух стран, а также в рамках Шанхайской организации сотрудничества, БРИКС и «Большой двадцатки» (G-20), где они обмениваются мнениями и обсуждают важнейшие проблемы регионального и глобального развития.

Была создана межправительственная комиссия по военно-техническому сотрудничеству под председательством министров обороны двух стран, которая обеспечивает необходимый импульс развития двусторонних отношений в военной области. Россия сегодня является единственной страной, с которой Индия создала консультативный механизм в области обороны на самом высоком уровне.

Активно развивается сотрудничество в космической, энергетической (в том числе в области атомной энергетики), нефтяной сферах, между ведомствами налажено тесное взаимодействие, идет активное обсуждение перспектив дальнейшей кооперации и создания совместных программ развития. Две страны имеют комплексную долгосрочную программу сотрудничества в области науки и техники. В 2010 г. эта программа была продлена до 2020 г. Повестка стратегического партнерства наших стран постоянно расширяется в зависимости от степени достигнутого взаимопонимания и выработки общих позиций по решению стратегических вопросов.

Эксперты констатируют поразительное совпадение позиций двух стран по ряду стратегических вопросов, таких как ядерная проблема, нераспространение оружия массового поражения и др. [10, с. 271]. В то же время Россия 
в своей политике умело сочетает и демонстрирует, с одной стороны, прагматизм, а с другой - учет интересов безопасности своего партнера.

В целом активно и на взаимовыгодных условиях наши отношения развиваются в сфере энергетики, особенно атомной, космических исследований, торговли и в военной области (поставка вооружения).

Что касается развития отношений в политической сфере, тут все не так однозначно и есть ряд определенных трудностей и проблем.

Да, мы успешно сотрудничаем с Индией по вопросам борьбы с международным терроризмом, здесь наши позиции во многом совпадают, в отличие от позиций западных стран. Россия на самом высоком политическом уровне поддерживает стремление Индии стать постоянным членом Совета Безопасности ООН. В Шанхайской организации сотрудничества Индия повысила свой статус от наблюдателя до полного члена ШОС.

\section{Проблемы и перспективы развития отношений}

Проблемы, которые существуют в сфере индийско-российских отношений, носят как объективный, так и субъективный характер.

Итак, еще во времена холодной войны были сделаны серьезные усилия, чтобы укреплять экономические, политические и культурные связи между нашими странами.

Но со временем, как полагают некоторые исследователи, традиции дружественных и тесных взаимоотношений России и Индии стали подвергаться девальвации, а все усилия правительств двух стран их реанимировать и поднять на прежний уровень воспринимались порой в индийском политическом сообществе как неактуальные («политический анахронизм»), а также как излишние [16, с. 239].

Это отразилось в некоторых внешнеполитических действиях и инициативах Индии.

1. Так, по очень важному для России вопросу, по вопросу создания США глобальной системы ПРО (противоракетной обороны), Индия заняла двойственную и двусмысленную позицию, что набросило тень на российскоиндийские отношения.

Ранее Индия, как и Россия, имела принципиальную позицию в данном вопросе и публично возражала против намерения президента Дж. Буша выйти из договора по ПРО для того, чтобы подготовить почву для развертывания системы противоракетной обороны. Но впоследствии, когда система была официально запущена, министр иностранных дел Индии Джасвант Сингх приветствовал действия США в Индийском парламенте, а индийское правительство фактически молчаливо одобрило расширение сотрудничества США и Индии в области противоракетной обороны. 
Поскольку Россия рассматривала разработку и внедрение системы ПРО (противоракетной обороны) как явную угрозу для ее безопасности, то такая амбивалентная позиция Индии в этом вопросе вызвала удивление и значительное разочарование среди российской политической элиты.

2. Индия и Россия еще в октябре 2000 г. в совместном заявлении отмечали, что они будут сотрудничать между собой и с другими странами для построения многополярного мира и справедливого и равноправного международного порядка, основанного на принципах суверенного равенства всех государств, территориальной целостности, невмешательства и уважения друг друга. Обе стороны также выразили решительное осуждение одностороннего применения силы в нарушение Устава ООН и вмешательства во внутренние дела других государств, в том числе под предлогом гуманитарной помощи. Это заявление было явно направлено против попыток США в одностороннем порядке применять силу против других стран без разрешения Совета Безопасности ООН.

Но весьма показательно, что новые совместные заявления по данному вопросу, подписанные позже, уже в 2010 г., хотя и осуждали применение силы или введение экономических санкций без разрешения Совета Безопасности, но уже не носили такого жесткого и категоричного характера, как ранее. Это указывало на явный сдвиг индийской внешней политики в сторону США, который произошел после заключения между странами так называемой «ядерной сделки».

3. В конце 1990-х - начале 2000-х годов было много рассуждений по поводу формирования трехстороннего альянса Россия - Индия - Китай (РИК). Действительно, эти страны регулярно встречались на общих площадках ШОС (Шанхайская организация сотрудничества), РИК и БРИКС, но ни одно из этих объединений не носило характера военного альянса и не было направлено против США и их союзников. Их единственной целью было и является поиск платформы для выработки общих позиций по глобальным вопросам и разработка планов взаимовыгодного сотрудничества. Вопрос о формировании стратегического альянса России, Индии и Китая, направленного против Запада, даже никогда не поднимался, в первую очередь потому, что, как дают ясно понять индийские и китайские партнеры, отношения каждой из этих стран с США являются более важными, чем их отношения друг с другом [10, с. 274].

4. Сегодня политические и культурные связи между нашими странами далеко не достигают того уровня, который имеется у Индии с ее западными партнерами. Еще во времена холодной войны многие индийцы получили качественное высшее образование в России, что внесло большой вклад в развитие этой страны. Но сегодня они предпочитают уезжать на учебу в западные страны, преимущественно в США, Великобританию, Австралию, 140 
и предпочитают российским университеты Китая или Сингапура. Таким образом, хотя культурный и политический диалог продолжается, однако, как считает Дэвид Малоун, это не более чем привычка, а Россия фактически находится вне культурного поля Индии [16, с. 239].

5. Серьезной проблемой в отношениях между двумя странами является относительно низкий уровень торгового оборота и инвестиционных потоков. В настоящее время стратегические двусторонние отношения между ведущими странами мира не могут успешно развиваться, не опираясь на солидную экономическую базу. Как показывает практика, именно широкие экономические связи придают сотрудничеству двух стран стратегический характер. Однако сегодня торговый обмен между Россией и Индией не соответствует потенциалу наших стран. Общий объем торговли между странами еще в 1990-е годы драматически сократился почти на $50 \%$ и так и не восстановился до сих пор в прежнем объеме. Хотя торговый оборот между Россией и Индией постепенно растет, тем не менее темпы его роста значительно ниже аналогичных показателей в торговле Индии с другими крупными партнерами. Например, в 2014 г. случился очередной его спад. По данным ФТС России, в этом году он уменьшился на 5,6\% по сравнению с 2013 г. [2]. В итоге Россия даже не вошла в первую десятку торговых партнеров Индии [5].

Еще в 2009 г. обе страны наметили цель: достигнуть к 2015 г. оборота во взаимной торговле 20 млрд долл. и предпринять для этого целый ряд эффективных мер. Чтобы вывести торговлю на новый уровень, предполагалось увеличить поток двусторонних инвестиций, реализовать совместные проекты в гражданском секторе, обмениваться инновационными технологиями и т.п.

Но в 2015 г. общий товарооборот между Россией и Индией хотя и вырос на 1\% по сравнению с 2014 г., но составил лишь 7,63 млрд долл. [4]. Реализация данной цели, как показала жизнь, выходит за рамки возможного. Поэтому во время очередного визита Президента РФ В.В. Путина в Индию стороны решили увеличить контрольные показатели роста оборота товаров и услуг до 30 млрд долл., но перенести сроки достижения этой цели на 2025 г. Запланировано, что уровень взаимных инвестиций к этому времени превысит 15 млрд долл. от каждой страны [10, с. 279].

Стороны понимают, что необходимо расширять и углублять сотрудничество в более широких секторах экономики, и уже есть определенный прогресс в инициировании и реализации крупных совместных проектов. Так, в Гуджарате при непосредственном участии России строится крупнейший в мире завод по производству бутилкаучука. Еще один совместный проект завод по сборке в городе Хайдарабаде крупноузловых машинокомплектов новейших пластиковых гусеничных бульдозеров Б-11 класса тяги 10 т.

Россия предложила производить в Индии знаменитые самолеты «Сухой Суперджет-100» и МC-21, успешно развивается прямая торговля алмазами 
между двумя странами. Такое сотрудничество имеет взаимовыгодный характер, притом что российская компания АЛРОСА является крупнейшим производителем алмазов в мире, в то время как Индия является ведущей страной в области их обработки.

Соглашение о поставках зенитных ракетных систем С-400 «Триумф» было подписано в 2016 г. по итогам встречи Президента РФ Владимира Путина и премьера Индии Нарендры Моди в индийском штате Гоа [3]. Сегодня обсуждаются детали подписания контракта на поставку в этом году Индии 48 вертолетов Ми-17В5 [1].

В последние годы наши страны активно инвестируют средства в экономики друг друга. Так, Индия собирается вкладывать средства в развитие в России промышленных парков, технологических платформ, фармацевтической продукции, удобрений, угля и энергии. В Индии ожидают российских инвестиций в крупные инфраструктурные проекты, телекоммуникации, энергетику и строительство дорог. Лидеры двух стран приветствовали инициативу фонда прямых инвестиций на сделку 2 млрд долл. между «Роснано» и его индийским партнером для реализации высокотехнологичных проектов. Во время последнего визита Путина в Индию (в 2016 г.) было также подписано много важных коммерческих контрактов между российскими и индийскими компаниями. Россия и Индия хотят постепенно перейти к взаимным платежам в национальных валютах. Это важно как для России, которая из-за западных санкций желает сберечь свои валютные резервы, так и для Индии, так как позволит ей более рационально использовать свои валютные поступления. Все это позволит укрепить рубль и рупию, будет способствовать уменьшению значимости доллара в глобальной экономике.

\section{Россия, Европа и Инаия.

В Европе ревниво наблюдают за процессом эволюции взаимоотношений России и Индии, не желая уступать нашей стране право приоритетного партнерства с новым глобальным актором.

Многие на Западе полагают, что Индия, Европа и Россия разделены глобальными вызовами, что у них отсутствуют общая стратегия и тактика выживания и развития в условиях глобализации [16, с. 242]. От того, как Европа и Россия будут решать эти проблемы, как будут отвечать на глобальные вызовы, будут зависеть их отношения с Индией как восходящей глобальной державой.

Сама же Индия продолжает поддерживать тесные отношения с США, особенно в сфере сотрудничества по ядерным проблемам. Она не скрывает, 
что очень заинтересована в развитии отношений с Китаем, а недавно был официально объявлен новый приоритет ее внешней политики под лозунгом «Смотреть на Восток» («Look East» policy).

Активизируется политика Индии на Ближнем Востоке. Взаимоотношения с этими странами, особенно с Израилем и странами Персидского залива, имеют, как полагают индийские эксперты, большой потенциал, могут служить укреплению безопасности в регионе.

Россия же может заинтересовать Индию в развитии сотрудничества в сфере энергетики, освоения космоса и торговли вооружениями. Правда, сегодня экономический и технологический потенциалы нашей страны недостаточно велики. Он не может полностью удовлетворить требованиям привилегированного стратегического партнерства и выйти на тот уровень взаимоотношений, который был у наших стран в недалеком прошлом.

Начало XXI в. было переломным моментом во взаимоотношениях России и Индии. Для России распад СССР оказался очень болезненным периодом, который сказался на ее экономике, политике и статусе в глобальном мире. Для Индии период усиления глобальной интеграции и конца однополярного мира, наоборот, стал благоприятным временем, способствовавшим подъему ее экономики и утверждению позиции глобального лидера.

Развитие процессов глобализации привело к изменению иерархического статуса двух стран: Индию стали рассматривать как нового глобального лидера, а Россию на Западе все чаще стали называть просто региональной державой. В результате некоторым стало казаться, что Индия и Россия поменялись местами, и теперь уже Россия более заинтересована в дружбе со своим старым партнером, еще в недавнем прошлом - развивающейся страной третьего мира [16, с. 243].

Однако существует и осознание того, что национальные интересы Индии и России не противоречат друг другу. Поэтому есть все возможности восстановления традиционных дружеских и взаимовыгодных отношений между двумя странами, какими они были во времена холодной войны.

В итоге Россия может попасть в «золотую середину» приоритетов внешней политики Индии. Это может дать ей определенное преимущество по сравнению со странами Запада или ее ближайшими соседями, с которыми отношения у нашего партнера уже в течение долгого времени весьма напряженные. Так, Кристоф Джафрелот пишет: «К большому разочарованию мы обнаруживаем, что Европейский союз едва ли присутствует на экране политического радара Индии. Европа вообще может вскоре обнаружить, что ее “задвинул в угол” этот лидер “нового азиатского порядка” и международный актор» $[15$, с. 357$]$.

И европейские страны, и Россия имеют большой интерес к Индии. Но преимущество России состоит в том, что она имеет большой опыт взаимо- 
действия с этой страной, а частые визиты лидеров и консультации наших министерств и ведомств в различных сферах стали давней традицией. Однако кто из них: ЕС или РФ - получит привилегированный статус партнера Индии, будет зависеть от успехов экономического развития России и характера интеграционных процессов в Европейском союзе.

Индия может в ближайшем будущем предпринять новые усилия для налаживания двусторонних отношений с ведущими европейскими странами. Данная задача в последнее время становилась для индийских политиков все более актуальной: в Индии с тревогой наблюдали, как администрация президента Б. Обамы буквально «обхаживает» Китай. Возникло опасение, что подобное сближение двух держав может привести к образованию «G-2» в составе США - Китай. В будущем такой союз мог негативно сказаться на взаимоотношениях этих стран с Индией, подорвать ее растущее экономическое влияние в регионе. Кроме того, Китай мог попытаться решить спорные пограничные вопросы со своим соседом самостоятельно, опираясь на поддержку Соединенных Штатов.

Если эти опасения оправдаются при новой администрации Белого дома, Индия, несомненно, обратится к Европе или России, чтобы вернуть утраченный геополитический баланс в регионе. При таком развитии событий - учитывая союзнические отношения ЕС с Соединенными Штатами - шансы у России стать приоритетным партнером Индии гораздо выше. Многое в ближайшем будущем будет зависеть от политики Д. Трампа по отношению к Китаю: решится ли он пойти на обострение отношений с этой страной или же сохранит во взаимоотношениях статус-кво.

Но что бы ни случилось в ближайшем будущем, Индия сегодня продолжает развивать двусторонние отношения с Россией, и это весьма удивляет и настораживает Запад [16, с. 245]. Но удивительного в этом мало. Отношения между Россией и Индией прошли испытания на прочность. Индия убедилась, что Россия в любых ситуациях является надежным партнером и поставщиком относительно дешевого, но современного оружия и энергоносителей.

Правда, это не мешает Индии в поисках новых поставщиков оружия обращаться к западным европейским странам, что грозит нанести ущерб традиционному российскому экспорту. Уже сегодня европейские экспортеры оружия представляют для России серьезных конкурентов.

\section{Некоторые выводы}

Известный эксперт Анурадха Ченой считает, что старая модель индийско-российских отношений устарела. Она нуждается в модернизации, должна стать более гибкой. Она должна отражать новую позицию, которую Индия 
занимает в глобальном мире, а сама Индия должна иметь геополитический простор для маневрирования в своей глобальной и региональной политике. Поэтому взаимоотношения и с Россией, и с Западной Европой должны быть, как полагает эксперт, сбалансированы и равноценны [9, с. 49].

Россия, по мнению индийского эксперта, сейчас активно восстанавливает свои позиции в глобальной иерархии. Это полностью вписывается в концепцию многополярного мира, какой ее представляют в Индии. То есть такого мира, где Индия имеет дело преимущественно с равноправными партнерами, партнерами, равными ей по экономической мощи и политическому влиянию. Индия гордится своими успехами в экономике и претендует на роль лидера в новом мировом порядке XXI в.

История и давние традиции дружбы Индии и России могут помочь преодолеть трудности становления новой модели взаимоотношений стран в многополярном мире, отражающей новую расстановку сил и приоритетов.

Сегодня Западная Европа и Россия становятся конкурентами за приоритетный статус во взаимоотношениях с Индией - восходящей глобальной державой. Однако у наших стран по-прежнему есть общие интересы и кроются они прежде всего в сфере безопасности. Кроме того, Индия заинтересована в российских энергоносителях.

В Индии отмечают, что хотя лидирующие позиции в новом многополярном мире сохраняют США, все более уверенно на мировой арене выступают Китай, Индия и Россия, а вместе с ними Бразилия. Эти страны успешно конвертируют усиление своей экономической мощи в политическое влияние. Страны же Западной Европы переживают стагнацию, связанную с рядом демографических, экономических и геополитических проблем. Между тем, по мнению индийских аналитиков, экономика России пока недостаточно устойчива. Этот факт оставляет Индии право выбора иных приоритетов своей внешней политики.

Объективно мыслящие индийские эксперты и политики считают, что Россия, несмотря на переживаемые экономические трудности, по-прежнему является глобальным лидером и региональной державой, имеющей огромное влияние в Европе, Азии (особенно в Центральной Азии, где Индия также имеет свои национальные интересы), на Кавказе и твердо отстаивает свои позиции в мире. При этом национальные интересы наших стран совпадают, а серьезные проблемы во взаимоотношениях маловероятны.

И все же приходится констатировать, что индо-российские взаимоотношения переживают некоторый спад. Если Индия переживает бурный экономический подъем, то в России наблюдается кризис. Для Индии сейчас весьма благоприятная геополитическая ситуация, которая позволяет ей укрепить свое международное влияние. Это дает повод Дели надеяться, что Индия может стать желаемым, привилегированным и доминирующим партнером для 
всех глобальных лидеров сразу: США, ЕС, Китая, России. Это даст ей шанс, как разборчивой невесте, широкого выбора среди них.

Сценарий будущего еще открыт, он далеко еще не предопределен и зависит от множества факторов, которые будут влиять на состояние мировой политической системы, делая ее подвижной и непредсказуемой.

Закончить же статью хотелось бы фразой из индийского учебника по внешней политике, в котором, по преимуществу, приводятся суждения, имеющие статус аксиомы: «Индия и Россия не могут позволить себе ослаблять и выхолащивать свои двусторонние отношения, поскольку обе страны нуждаются друг в друге. Поэтому они должны и дальше развивать свое взаимодействие и сотрудничество в экономике, особенно в сфере обеспечения безопасности. В данном контексте актуальной является задача проанализировать и провести аудит текущего состояния партнерства. Как метко выразился российский посол А.М. Кадакин ${ }^{3}$ “Индия - ближайший друг России”. Обратное также справедливо» [12, с. 38].

\section{Библиография}

1. Контракт на поставку Индии 48 вертолетов Ми-17В5 может быть заключен до конца года // URL: http://www.vedomosti.ru/business/news/2017/02/14/677552-indii-mi-17v5 (Дата обращения: 03.04.2017.)

2. Портал внешнеэкономической информации. Министерство экономического развития PФ // URL: http://www.ved.gov.ru/exportcountries/in/in_ru_relations/in_ru_trade/ (Дата обращения: 03.04.2017.)

3. Путин договорился о поставках в Индию ЗРC C-400 «Триумф» // URL: http://www. 1tvnet.ru/content/show/putin-dogovorilsya-o-postavkah-v-indiyu-zrs-s-400-triumf_36608.html (Дата обращения: 03.04.2017.)

4. Торговый оборот между Россией и Индией за 2015 год // URL: http://www. rusexporter.ru/research/country/detail/4313/ (Дата обращения: 03.04. 2017.)

5. Эксперты: Полноценному сотрудничеству между Россией и Индией мешают США // URL: https://www.ridus.ru/news/165624 (Дата обращения: 03.04.2017.)

6. Abhyankar, Rajendra M. Introduction // West Asia and the Region: Defining India's Role / Ed. by Rajendra M. Abhyankar. New Delhi: Academic Foundation, 2008. 237 p.

7. Bandyopadhyaya, J. The Making of India's Foreign Policy: Determinants, institutions, processes, and personalities. Allied Publishers. New Delhi: Allied Publishers PvtLmd, 2013. 337 p.

8. India's Foreign Policy Retrospect and Prospect / Ed. by S. Genguly. New Delhi: Oxford University Press. 2010 // URL: http://dev.1947partitionarchive.org/node/545 (Дата обращения: 03.04.2017.)

9. Chenoy, Anuradha M. India and Russia: Allies in the International Political System // South Asian Survey. 2008. N 15/1. P. 49-62.

10. Dubey, Muchkund. India's Foreign Policy. Coping with Changing World. New Delhi: Orient BlackSwan Privet Limited, 2016. 446 p.

3. Посол РФ в Индии А.М. Кадакин скоропостижно скончался в январе 2017 г. Прим. автора. 
11. India and West Asia in the Era of Globalisation. New Delhi: New Century Publications, 2010. 107 p

12. India Foreign Policy. Calcutta: Calicut University P.O, Malappuram Kerala, n/d. 76 p. // URL: http://www.universityofcalicut.info/cuonline/exnotif/ex5437.pdf (Дата обращения: 03.04.2017.)

13. India's Foreign Policy. Module 6. India and the World // URL: http://download.nos.org/ srsec317newE/317EL26.pdf (Дата обращения: 03.04.2017.)

14. Foreign policy of India // URL: http://www.slideshare.net/duawahab/foreign-policy-ofindia-36407477 (Дата обращения: 03.04.2017.)

15. Jaffrelot, Christophe. India and the European Union: The Charade of a Strategic Partnership. Paris: Centre for International Studies and Research, 2006. 464 p.

16. Malone, David M. Does the Elephant Dance? Contemporary Indian Foreign Policy. New Delhi: Oxford India Paperbacks, 2014. 425 p.

17. Mohan C. Raja. Draft paper presented at a Seminar in Beijing by China Reform Forum and the Carnegie Endowment for International Peace, Beijing, May 26, 2006 // URL: http://carnegieendowment.org/files/Mohan.pdf (Дата обращения: 03.04.2017.)

18. Panagariya A. India: The Emerging Giant. New York: Oxford University Press, 2008. 538 c. // URL: http://ru.bookzz.org/book/779813/82d967 (Дата обращения: 03.04.2017.)

19. Singh, Jasjeet. India's Foreign Policy // URL: http://www.slideshare.net/duawahab/foreignpolicy-of-india-36407477 (Дата обращения: 03.04.2017.)

\section{References}

Abhyankar, Rajendra M. Introduction // West Asia and the Region: Defining India's Role / Ed. by Rajendra M. Abhyankar. New Delhi: Academic Foundation, 2008. 237 p.

Bandyopadhyaya, J. The Making of India's Foreign Policy: Determinants, institutions, processes, and personalities. Allied Publishers. New Delhi: Allied Publishers PvtLmd, 2013. 337 p.

Chenoy, Anuradha M. India and Russia: Allies in the International Political System // South Asian Survey. 2008. N 15/1. P. 49-62.

Dubey, Muchkund. India's Foreign Policy. Coping with Changing World. New Delhi: Orient BlackSwan Privet Limited, 2016. 446 p.

Foreign policy of India // URL: http://www.slideshare.net/duawahab/foreign-policy-of-india36407477 (Data obrashhenija: 03.04.2017.)

India and West Asia in the Era of Globalisation. New Delhi: New Century Publications, 2010. $107 \mathrm{p}$.

India Foreign Policy. Calcutta: Calicut University P.O, Malappuram Kerala, n/d. 76 p. // URL: http://www.universityofcalicut.info/cuonline/exnotif/ex5437.pdf (Data obrashhenija: 03.04.2017.)

India's Foreign Policy Retrospect and Prospect / Ed. by S. Genguly. New Delhi: Oxford University Press. 2010 // URL: http://dev.1947partitionarchive.org/node/545 (Data obrashhenija: 03.04.2017.)

India's Foreign Policy. Module 6. India and the World // URL: http://download.nos.org/ srsec317newE/317EL26.pdf (Data obrashhenija: 03.04.2017.)

Jaffrelot, Christophe. India and the European Union: The Charade of a Strategic Partnership. Paris: Centre for International Studies and Research, 2006. 464 p.

Jeksperty: Polnocennomu sotrudnichestvu mezhdu Rossiej i Indiej meshajut SShA // URL: https://www.ridus.ru/news/165624 (Data obrashhenija: 03.04.2017). 


\section{РОССИЯ И МИР В ХХІ ВЕКЕ}

Kontrakt na postavku Indii 48 vertoletov Mi-17V5 mozhet byt' zakljuchen do konca goda // URL: http://www.vedomosti.ru/business/news/2017/02/14/677552-indii-mi-17v5 (Data obrashhenija: 03.04.2017.)

Malone, David M. Does the Elephant Dance? Contemporary Indian Foreign Policy. New Delhi: Oxford India Paperbacks, 2014. 425 p.

Mohan C. Raja. Draft paper presented at a Seminar in Beijing by China Reform Forum and the Carnegie Endowment for International Peace, Beijing, May 26, 2006 // URL: http://carnegieendowment.org/files/Mohan.pdf (Data obrashhenija: 03.04.2017.)

Panagariya A. India: The Emerging Giant. New York: Oxford University Press, 2008. 538 c. // URL: http://ru.bookzz.org/book/779813/82d967 (Data obrashhenija: 03.04.2017.)

Portal vneshnejekonomicheskoj informacii. Ministerstvo jekonomicheskogo razvitija RF // URL: http://www.ved.gov.ru/exportcountries/in/in_ru_relations/in_ru_trade/ (Data obrashhenija: 03.04.2017.)

Putin dogovorilsja o postavkah v Indiju ZRS S-400 «Triumf» // URL: http://www. 1tvnet.ru/content/show/putin-dogovorilsya-o-postavkah-v-indiyu-zrs-s-400-triumf_36608.html (Data obrashhenija: 03.04.2017.)

Singh, Jasjeet. India's Foreign Policy // URL: http:/www.slideshare.net/duawahab/foreignpolicy-of-india-36407477 (Data obrashhenija: 03.04.2017.)

Torgovyj oborot mezhdu Rossiej i Indiej za 2015 god // URL: http://www.rusexporter.ru/ research/country/detail/4313/ (Data obrashhenija: 03.04.2017.) 